\title{
Development and experimental test of support vector machines virtual screening method for searching Src inhibitors from large compound libraries
}

\author{
Bucong Han ${ }^{1,2,3}$, Xiaohua $\mathrm{Ma}^{3}$, Ruiying Zhao ${ }^{4}$, Jingxian Zhang ${ }^{3}$, Xiaona Wei ${ }^{2,3}$, Xianghui Liư ${ }^{3}$, Xin Liư \\ Cunlong Zhang ${ }^{1}$, Chunyan Tan ${ }^{1}$, Yuyang Jiang ${ }^{1 *}$ and Yuzong Chen ${ }^{1,2,3^{*}}$
}

\begin{abstract}
Background: Src plays various roles in tumour progression, invasion, metastasis, angiogenesis and survival. It is one of the multiple targets of multi-target kinase inhibitors in clinical uses and trials for the treatment of leukemia and other cancers. These successes and appearances of drug resistance in some patients have raised significant interest and efforts in discovering new Src inhibitors. Various in-silico methods have been used in some of these efforts. It is desirable to explore additional in-silico methods, particularly those capable of searching large compound libraries at high yields and reduced false-hit rates.

Results: We evaluated support vector machines (SVM) as virtual screening tools for searching Src inhibitors from large compound libraries. SVM trained and tested by 1,703 inhibitors and 63,318 putative non-inhibitors correctly identified 93.53\% 95.01\% inhibitors and 99.81\% 99.90\% non-inhibitors in 5-fold cross validation studies. SVM trained by 1,703 inhibitors reported before 2011 and 63,318 putative non-inhibitors correctly identified 70.45\% of the 44 inhibitors reported since 2011, and predicted as inhibitors 44,843 (0.33\%) of 13.56M PubChem, 1,496 (0.89\%) of $168 \mathrm{~K} \mathrm{MDDR}$, and 719 (7.73\%) of 9,305 MDDR compounds similar to the known inhibitors.

Conclusions: SVM showed comparable yield and reduced false hit rates in searching large compound libraries compared to the similarity-based and other machine-learning VS methods developed from the same set of training compounds and molecular descriptors. We tested three virtual hits of the same novel scaffold from in-house chemical libraries not reported as Src inhibitor, one of which showed moderate activity. SVM may be potentially explored for searching Src inhibitors from large compound libraries at low false-hit rates.
\end{abstract}

Keywords: Src, c-src, Computer aided drug design, Kinase inhibitor, Virtual screening, Support vector machine

\section{Background}

Src promotes tumour invasion and metastasis, facilitates VEGF-mediated angiogenesis and survival in endothelial cells, and enhances growth factor driven proliferation in fibroblasts [1]. It is one of the multiple kinase targets of

\footnotetext{
* Correspondence: jiangyy@sz.tsinghua.edu.cn; phacyz@nus.edu.sg ${ }^{1}$ The Key Laboratory of Chemical Biology, Guangdong Province, The Graduate School at Shenzhen, Tsinghua University, Shenzhen, Guangdong 518055, People's Republic of China

${ }^{2}$ Computation and Systems Biology, Singapore-MIT Alliance, National University of Singapore, E4-04-10, 4 Engineering Drive 3, Singapore 117576, Singapore

Full list of author information is available at the end of the article
}

a number of multi-target kinase inhibitors effective in the clinical treatment of leukemia and in clinical trials of other cancers [2-4]. The successes and problems of these inhibitors have raised significant interest and efforts in discovering new Src inhibitors [5-7]. Several in-silico methods have been used for facilitating the search and design of Src inhibitors, which include pharmacophore [8], Quantitative Structure Activity Relationship (QSAR) [9], and molecular docking [6].

While these in-silico methods have shown impressive capability in the identification of potential Src inhibitors, their applications may be affected by such problems as the

\section{(C) Chemistry Central}


vastness and sparse nature of chemical space needing to be searched, complexity and flexibility of target structures, difficulties in accurately estimating binding affinity and solvation effects on molecular binding, and limited representativeness of training active compounds [10-12]. It is desirable to explore other in-silico methods that complement these methods by expanded coverage of chemical space, increased screening speed, and reduced false-hit rates without necessarily relying on the modelling of target structural flexibility, binding affinity and salvation effects.

Support vector machines (SVM) has recently been explored as a promising ligand-based virtual screening (VS) method that produces high yields and low false-hit rates in searching active agents of single and multiple mechanisms from large compound libraries [13] and in identifying active agents of diverse structures [13-17]. Good VS performance can also be achieved by SVM trained from sparsely distributed active compounds [18]. SVM classifies active compounds based on the separation of active and inactive compounds in a hyperspace constructed by their physicochemical properties rather than structural similarity to active compounds per se, which has the advantage of not relying on the accurate computation of structural flexibility, activity-related features, binding affinity and solvation effects. Moreover, the fast speed of SVM enables efficient search of vast chemical space. Therefore, SVM may be a potentially useful VS tool to complement other in-silico methods for searching Src inhibitors from large libraries.

In this work, we developed a SVM VS model for identifying Src inhibitors, and evaluated its performance by both 5 -fold cross validation test and large compound database screening test. In 5-fold cross validation test, a dataset of Src inhibitors and non-inhibitors was randomly divided into 5 groups of approximately equal size, with 4 groups used for training a SVM VS tool and 1 group used for testing it, and the test process is repeated for all 5 possible compositions to derive an average VS performance. In large database screening test, a SVM VS tool was developed by using Src inhibitors published before 2011, its yield (percent of known inhibitors identified as virtual-hits) was estimated by using Src inhibitors reported since 2011 and not included in the training datasets, virtual-hit rate and false-hit rate in searching large libraries were evaluated by using $13.56 \mathrm{M}$ PubChem and 168K MDDR compounds, and an additional set of 9,305 MDDR compounds similar in structural and physicochemical properties to the known Src inhibitors.

Moreover, VS performance of SVM was compared to those of two similarity-based VS methods, Tanimoto similarity searching and $\mathrm{k}$ nearest neighbour $(\mathrm{kNN})$, and an alternative but equally popularly used machine learning method, probabilistic neural network (PNN) method, based on the same training and testing datasets (same sets of PubChem and MDDR compounds) and molecular descriptors. In a study that compares the performance of SVM to 16 classification methods and 9 regression methods, it has been reported that SVMs shows mostly good performances both on classification and regression tasks, but other methods proved to be very competitive [19]. Therefore, it is useful to evaluate the VS performance of SVM in searching large compound libraries by comparison with those of both similarity-based approaches and other typical machine learning method.

PubChem and MDDR contain high percentages of inactive compounds significantly different from the known Src inhibitors, and the easily distinguishable features may make VS enrichments artificially good [20]. Therefore, VS performance may be more strictly tested by using subsets of compounds that resemble the physicochemical properties of the known Src inhibitors so that enrichment is not simply a separation of trivial physicochemical features [21]. To further evaluate whether our SVM VS tool predict Src inhibitors and non-inhibitors rather than membership of certain compound families, distribution of the predicted active and inactive compounds in the compound families were analyzed.

\section{Materials and methods \\ Compound collections and construction of training and testing datasets}

We collected 1,703 Src inhibitors reported before 2011, with $\mathrm{IC} 50<10 \mu \mathrm{M}$, from the literatures [22-26] and the BindingDB database [27]. The inhibitor selection criterion of IC $50<10 \mu \mathrm{M}$ was used because it covers most of the reported HTS and VS hits $[28,29]$. The structures of representative Src inhibitors are shown in Figure 1. As few non-inhibitors have been reported, putative noninhibitors were generated by using our method for generating putative inactive compounds $[13,18]$. This method requires no knowledge of known inactive compounds and active compounds of other target classes, which enables more expanded coverage of the "noninhibitor" chemical space. Although the yet-to-be-discovered inhibitors are likely distributed in some of these "non-inhibitor" families, a substantial percentage of these inhibitors are expected to be identified as inhibitors rather than non-inhibitors even-though representatives of their families are putatively assigned as non-inhibitors [13]. 13.56M PubChem and $168 \mathrm{~K}$ MDDR compounds were grouped into 8,423 compound families by clustering them in the chemical space defined by their molecular descriptors [30,31]. The number of generated families is consistent with the 12,800 compound-occupying neurons (regions of topologically close structures) for 26.4 million compounds of up to 11 atoms [32], and the 2,851 clusters for 171,045 natural products [33]. 
<smiles>COc1cc(Nc2c(C#N)cnc3cc(OCCCN4CCN(C)CC4)c(OC)cc23)c(Cl)cc1Cl</smiles><smiles>CCN(CC)CCNC(=O)c1c(C)[nH]c(/C=C2\C(=O)Nc3ccc(F)cc32)c1C</smiles><smiles>Cn1c(=O)c(-c2c(Cl)cccc2Cl)cc2cnc(N)nc21</smiles>

$$
\begin{aligned}
& \text { J. Med. Chem. } \\
& 41 \text { (1998) 3276-3292 } \\
& \text { IC50 }=0.26 \mu \mathrm{m}
\end{aligned}
$$<smiles>CCOC(=O)OCCCCC(n1nc(-c2ccc(Cl)cc2)c2c(N)ncnc21)C(C)(C)C</smiles><smiles>COc1cc2c(cc1OC)Nc1nc[nH]c(=O)c1C2</smiles>

Bioorg. Med. Chem. Lett. 5 (1995) 1007-1010

$1 \mathrm{CSO}=0.5 \mu \mathrm{m}$<smiles>Nc1ncnc2c1c(-c1cccc(O)c1)cn2C1CCCC1</smiles>

Bioorg. Med. Chem. Lett. 11 (2001) $853-856$

IC50 $=0.001 \mu \mathrm{m}$

Figure 1 The structures of representative c-Src inhibitors.

Our collected Src inhibitors are distributed in 493 families. Because of the extensive efforts in searching kinase inhibitors from known compound libraries, the number of undiscovered Src inhibitor families in PubChem and MDDR databases is expected to be relatively small, most likely no more than several hundred families. The ratio of the discovered and undiscovered inhibitor families (hundreds) and the families that contain no known Src inhibitor $(8,423$ based on the current versions of PubChem and MDDR) is expected to be $<15 \%$. Therefore, putative non-inhibitor training dataset can be generated by extracting a few representative compounds from each of those families that contain no known inhibitor, with a maximum possible "wrong" classification rate of $<15 \%$ even when all of the undiscovered inhibitors are misplaced into the non-inhibitor class. The noise level generated by up to $15 \%$ "wrong" negative family representation is expected to be substantially smaller than the maximum 50\% false-negative noise level tolerated by SVM [16]. Based on earlier studies $[13,18]$ and this work, it is expected that a substantial percentage of the un-discovered inhibitors in the putative "non-inhibitor" families can be classified as inhibitor despite their family representatives are placed into the non-inhibitor training sets.

In the database screening test, $60.1 \%$ of the families that contain Src inhibitors reported since 2011 [34-39] are not covered by the Src inhibitor training dataset (inhibitors reported before 2011). The representative compounds of these families, none of which happen to be Src inhibitor, were deliberately placed into the inactive training sets because the inhibitors in these families are not supposed to be known in our study. As shown in earlier studies [13,18] and in this work, a substantial percentage of the inhibitors in these misplaced inhibitor-containing "non-inhibitor" families were 
predicted as inhibitors by our SVM VS tool. Moreover, a small percentage of the compounds in these putative non-inhibitor datasets are expected to be un-reported and un-discovered inhibitors, their presence in these datasets is not expected to significantly affect the estimated false hit rate of SVM.

\section{Molecular descriptors}

Molecular descriptors are quantitative representations of structural and physicochemical features of molecules, which have been extensively used in deriving structureactivity relationships $[40,41]$, quantitative structure activity relationships $[42,43]$ and VS tools [44-51]. A total of $981 \mathrm{D}$ and 2D descriptors derived by using our software [52] were used in this work. These descriptors and the relevant references are given in Table 1, which include 18 descriptors in the class of simple molecular properties, 3 descriptors in the class of chemical properties, 35 descriptors in the class of molecular connectivity and shape, 42 descriptors in the class of electro-topological state.

\section{Support vector machines method}

The process of training and using a SVM VS model for screening compounds based on their molecular descriptors is schematically illustrated in Figure 2. SVM is based on the structural risk minimization principle of statistical learning theory $[57,58]$, which consistently shows outstanding classification performance, is less penalized by sample redundancy, and has lower risk for over-fitting [59,60]. In linearly separable cases, SVM constructs a hyper-plane to separate active and inactive classes of compounds with a maximum margin. A compound is represented by a vector $\boldsymbol{x}_{i}$ composed of its molecular descriptors. The hyper-plane is constructed by finding another vector $\mathbf{w}$ and a parameter $b$ that minimizes $\|\mathbf{w}\|^{2}$ and satisfies the following conditions:

$$
\begin{aligned}
& \mathbf{w} \cdot \mathbf{x}_{i}+b \geq+1, \text { for } y_{i}=+1 \quad \text { Class } 1 \text { (active) } \\
& \mathbf{w} \cdot \mathbf{x}_{i}+b \leq-1, \text { for } y_{i}=-1 \quad \text { Class } 2 \text { (inactive) }
\end{aligned}
$$

where $y_{i}$ is the class index, $\mathbf{w}$ is a vector normal to the hyperplane, $|b| /\|\mathbf{w}\|$ is the perpendicular distance from the hyperplane to the origin and $\|\mathbf{w}\|^{2}$ is the Euclidean norm of $\mathbf{w}$. Base on $\mathbf{w}$ and $b$, a given vector $\boldsymbol{x}$ can be classified by $f(x)=\operatorname{sign}[(\mathbf{w} \cdot \mathbf{x})+b]$. A positive or negative $f(x)$ value indicates that the vector $\mathbf{x}$ belongs to the active or inactive class respectively.

In nonlinearly separable cases, which almost always occur in classifying compounds of diverse structures [14-17,50,61-63], SVM maps the input vectors into a higher dimensional feature space by using a kernel function $K\left(\mathbf{x}_{i}, \mathbf{x}_{j}\right)$. We used RBF kernel $K\left(\mathbf{x}_{i}, \mathbf{x}_{j}\right)=e^{-\left\|\mathbf{x}_{j}-\mathbf{x}_{i}\right\|^{2} / 2 \sigma^{2}}$ which has been extensively used and consistently shown better performance than other kernel functions [64-66]. Linear SVM can then applied to this feature space based on the following decision function: $f(\mathbf{x})=\operatorname{sign}\left(\sum_{i=1}^{l} \alpha_{i}^{0} y_{i} K\left(\mathbf{x}, \mathbf{x}_{i}\right)+b\right)$, where the coefficients $\alpha_{i}^{0}$ and $b$ are determined by maximizing the following Langrangian expression: $\sum_{i=1}^{l} \alpha_{i}-\frac{1}{2} \sum_{i=1}^{l} \sum_{j=1}^{l} \alpha_{i} \alpha_{j} y_{i} y_{j} K\left(\mathbf{x}_{i}, \mathbf{x}_{j}\right) \quad$ under the conditions $\alpha_{i} \geq 0$ and $\sum_{i=1}^{l} \alpha_{i} y_{i}=0$. A positive or negative $f(\boldsymbol{x})$ value indicates that the vector $x$ belongs to the active or inactive class respectively.

\begin{tabular}{|c|c|c|}
\hline Descriptor class & $\begin{array}{l}\text { No of } \\
\text { descriptors in } \\
\text { class }\end{array}$ & Descriptors \\
\hline $\begin{array}{l}\text { Simple molecular } \\
\text { properties [53] }\end{array}$ & 18 & $\begin{array}{l}\text { Number of } \mathrm{C}, \mathrm{N}, \mathrm{O}, \mathrm{P}, \mathrm{S}, \text { Number of total atoms, Number of rings, Number of bonds, Number of non- } \mathrm{H} \\
\text { bonds, Molecular weight, Number of rotatable bonds, number of } \mathrm{H} \text {-bond donors, number of } \mathrm{H}- \\
\text { bond acceptors, Number of } 5 \text {-member aromatic rings, Number of } 6 \text {-member aromatic rings, } \\
\text { Number of } \mathrm{N} \text { heterocyclic rings, Number of } \mathrm{O} \text { heterocyclic rings, Number of S heterocyclic rings. }\end{array}$ \\
\hline Chemical properties [54] & 3 & Sanderson electronegativity, Molecular polarizability, aLogp \\
\hline $\begin{array}{l}\text { Molecular Connectivity and } \\
\text { shape }[53,55]\end{array}$ & 35 & $\begin{array}{l}\text { Schultz molecular topological index, Gutman molecular topological index, Wiener index, Harary } \\
\text { index, Gravitational topological index, Molecular path count of length 1-6, Total path count, } \\
\text { Balaban Index J, 0-2th valence connectivity index, 0-2th order delta chi index, Pogliani index, 0-2th } \\
\text { Solvation connectivity index, 1-3th order Kier shape index, 1-3th order Kappa alpha shape index, } \\
\text { Kier Molecular Flexibility Index, Topological radius, Graph-theoretical shape coefficient, Eccentricity, } \\
\text { Centralization, Logp from connectivity. }\end{array}$ \\
\hline $\begin{array}{l}\text { Electro-topological state } \\
{[53,56]}\end{array}$ & 42 & $\begin{array}{l}\text { Sum of Estate of atom type sCH3, dCH2, ssCH2, dsCH, aaCH, sssCH, dssC, aasC, aaaC, sssC, sNH3, } \\
\text { sNH2, ssNH2, dNH, ssNH, aaNH, dsN, aaN, sssN, ddsN, aOH, sOH, ssO, sSH; Sum of Estate of all heavy } \\
\text { atoms, all C atoms, all hetero atoms, Sum of Estate of H-bond acceptors, Sum of H Estate of atom } \\
\text { type } \mathrm{HsOH}, \mathrm{HdNH}, \mathrm{HsSH}, \mathrm{HsNH} 2, \mathrm{HssNH}, \mathrm{HaaNH}, \mathrm{HtCH}, \mathrm{HdCH} 2, \mathrm{HdsCH}, \mathrm{HaaCH}, \mathrm{HCsats}, \mathrm{HCsatu} \text {, } \\
\text { Havin, Sum of H Estate of H-bond donors }\end{array}$ \\
\hline
\end{tabular}

Table 1 Molecular descriptors used in this work 


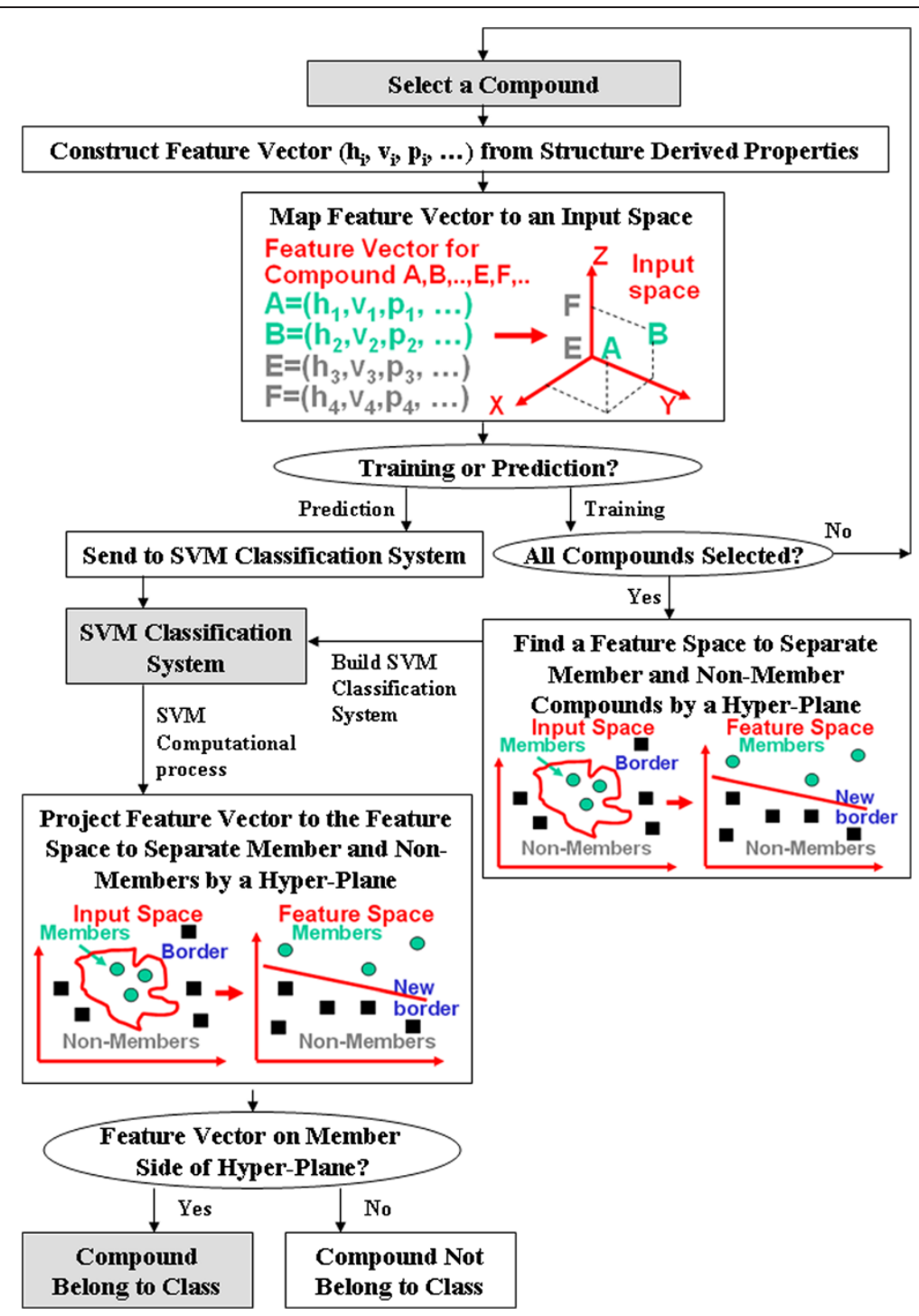

Figure 2 The process of training and using a SVM VS model for screening compounds. Schematic diagram is illustrating the process of the training a prediction model and using it for predicting active compounds of a compound class from their structurally-derived properties (molecular descriptors) by using support vector machines. A, B, E, F and $\left(h_{j}, p_{j}, v j, \ldots\right)$ represents such structural and physicochemical properties as hydrophobicity, volume, polarizability, etc.

In developing our SVM VS tool, a hard margin $\mathrm{c}=100,000$ was used. The margin parameter $\mathrm{c}$ is penalty parameter that controls the trade-off between the training errors and sample separation. Increasing c imposes a higher penalty for training errors. Our chosen value corresponds to a very high penalty. The performance of SVM was evaluated by 5 -fold cross-validation test. Table 2 shows the results of the 5 -fold cross validation of SVM VS models of Src inhibitors and putative noninhibitors. After the 5-fold cross-validation, the $\sigma$ values were found to be 1.2 based on the average VS performance for the model development. Its performance indicators can be derived from the numbers of true positives $T P$ (true inhibitors), true negatives TN (true non- inhibitors), false positives $F P$ (false inhibitors), and false negatives $F N$ (false non-inhibitors). Src inhibitor and non-inhibitor prediction accuracies are given by sensitivity $S E=T P /(T P+F N)^{*} 100$ and specificity $S P=T N /(T N+F P)$ *100 respectively. Prediction accuracies have also been frequently measured by overall prediction accuracy $(Q)$ and Matthews correlation coefficient $(C)$ [67]

$$
\begin{aligned}
& Q=\frac{T P+T N}{T P+T N+F P+F N} \\
& C=\frac{T P * T N-F N * F P}{\sqrt{(T P+F N)(T P+F P)(T N+F N)(T N+F P)}}
\end{aligned}
$$


Table 2 Performance of SVM for identifying Src inhibitors and non-inhibitors evaluated by 5-fold cross validation study

\begin{tabular}{|c|c|c|c|c|c|c|c|c|c|c|}
\hline \multirow{2}{*}{$\begin{array}{l}\text { Cross - } \\
\text { validation }\end{array}$} & \multicolumn{4}{|c|}{ Src inhibitors } & \multicolumn{4}{|c|}{ Src non-inhibitors } & \multirow[t]{2}{*}{$\mathbf{Q}$} & \multirow[t]{2}{*}{$\mathrm{C}$} \\
\hline & $\begin{array}{l}\text { No of training/ testing } \\
\text { inhibitors }\end{array}$ & TP & $\mathrm{FN}$ & $\mathrm{SE}$ & $\begin{array}{l}\text { No of training/testing } \\
\text { non-inhibitors }\end{array}$ & TN & FP & SP & & \\
\hline 1 & $1362 / 341$ & 320 & 21 & $93.84 \%$ & $50654 / 12664$ & 12651 & 13 & $99.90 \%$ & $99.74 \%$ & 0.948 \\
\hline 2 & $1362 / 341$ & 324 & 17 & $95.01 \%$ & $50654 / 12664$ & 12650 & 14 & $99.89 \%$ & $99.76 \%$ & 0.953 \\
\hline 3 & $1362 / 341$ & 324 & 17 & $95.01 \%$ & $50654 / 12664$ & 12640 & 24 & $99.81 \%$ & $99.68 \%$ & 0.939 \\
\hline 4 & $1363 / 340$ & 318 & 22 & $93.53 \%$ & $50655 / 12663$ & 12642 & 21 & $99.83 \%$ & $99.67 \%$ & 0.935 \\
\hline 5 & $1363 / 340$ & 322 & 18 & $94.71 \%$ & $50655 / 12663$ & 12643 & 20 & $99.84 \%$ & $99.71 \%$ & 0.943 \\
\hline Average & & & & $94.42 \%$ & & & & $99.85 \%$ & $99.71 \%$ & 0.944 \\
\hline SD & & & & 0.0069 & & & & 0.0004 & 0.0004 & 0.0072 \\
\hline SE & & & & 0.0031 & & & & 0.0002 & 0.0002 & 0.0032 \\
\hline
\end{tabular}

In the large database screening tests, the yield and falsehit rate are given by $T P /(T P+F N)$ and $F P /(T P+F P)$ respectively.

\section{Tanimoto similarity searching method}

Compounds similar to at least one known Src inhibitor in a training dataset can be identified by using the Tanimoto coefficient $\operatorname{sim}(i, j)[68]$

$$
\operatorname{sim}(i, j)=\frac{\sum_{d=1}^{l} x_{d i} x_{d j}}{\sum_{d=1}^{l}\left(x_{d i}\right)^{2}+\sum_{d=1}^{l}\left(x_{d j}\right)^{2}-\sum_{d=1}^{l} x_{d i} x_{d j}}
$$

where $l$ is the number of molecular descriptors. A compound $i$ is considered to be similar to a known active $j$ in the active dataset if the corresponding $\operatorname{sim}(i, j)$ value is greater than a cut-off value. In this work, the similarity search was conducted for MDDR compounds. Therefore, in computing $\operatorname{sim}(i, j)$, the molecular descriptor vectors $\mathbf{x}_{i} \mathrm{~s}$ were scaled with respect to all of the MDDR compounds. The cut-off values for similarity compounds are typically in the range of 0.8 to 0.9 [21,69]. A stricter cut-off value of 0.9 was used in this study.

\section{K-nearest neighbour method}

kNN measures the Euclidean distance $D=\sqrt{\left\|\mathbf{x}-\mathbf{x}_{i}\right\|^{2}}$ between a compound $\boldsymbol{x}$ and each individual inhibitor or non-inhibitor $\boldsymbol{x}_{i}$ in the training set [70]. A total of $k$ number of vectors nearest to the vector $\boldsymbol{x}$ are used to determine the decision function $f(\boldsymbol{x})$ :

$$
\hat{f}(\mathbf{x}) \longleftarrow \arg \max _{v \in V} \sum_{i=1}^{k} \delta\left(\nu, f\left(\mathbf{x}_{i}\right)\right)
$$

Where $\delta(a, b)=1$ if $a=b$ and $\delta(a, b)=0$ if $a \neq b$, argmax is the maximum of the function, $\mathrm{V}$ is a finite set of vectors $\{\mathrm{v} 1, \ldots, \mathrm{vs}\}$ and $\hat{f}(\mathbf{x})$ is an estimate of $\mathrm{f}(\mathrm{x})$. Here estimate refers to the class of the majority compound group (i.e. inhibitors or non-inhibitors) of the $\mathrm{k}$ nearest neighbours. The performance of kNN was evaluated by 5 -fold crossvalidation in the same manner as in SVM and Table 3 shows the results of the 5 -fold cross-validation results of

\begin{tabular}{|c|c|c|c|c|c|c|c|c|c|c|}
\hline \multirow{2}{*}{$\begin{array}{l}\text { Cross - } \\
\text { validation }\end{array}$} & \multicolumn{4}{|c|}{ Src inhibitors } & \multicolumn{4}{|c|}{ Src non-inhibitors } & \multirow[t]{2}{*}{$\mathbf{Q}$} & \multirow[t]{2}{*}{$\mathrm{C}$} \\
\hline & $\begin{array}{l}\text { No of training/ testing } \\
\text { inhibitors }\end{array}$ & TP & FN & SE & $\begin{array}{l}\text { No of training/testing } \\
\text { non-inhibitors }\end{array}$ & $\mathrm{TN}$ & FP & SP & & \\
\hline 1 & $1362 / 341$ & 302 & 39 & $88.56 \%$ & $50654 / 12664$ & 12635 & 29 & $99.77 \%$ & $99.48 \%$ & 0.896 \\
\hline 2 & $1362 / 341$ & 313 & 28 & $91.79 \%$ & $50654 / 12664$ & 12620 & 44 & $99.65 \%$ & $99.45 \%$ & 0.894 \\
\hline 3 & $1362 / 341$ & 311 & 30 & $91.20 \%$ & $50654 / 12664$ & 12610 & 54 & $99.57 \%$ & $99.35 \%$ & 0.878 \\
\hline 4 & $1363 / 340$ & 316 & 24 & $92.94 \%$ & $50655 / 12663$ & 12619 & 44 & $99.65 \%$ & $99.48 \%$ & 0.901 \\
\hline 5 & $1363 / 340$ & 302 & 38 & $88.82 \%$ & $50655 / 12663$ & 12632 & 31 & $99.76 \%$ & $99.47 \%$ & 0.895 \\
\hline Average & & & & $90.66 \%$ & & & & $99.68 \%$ & $99.44 \%$ & 0.893 \\
\hline SD & & & & 0.0191 & & & & 0.0008 & 0.0005 & 0.0085 \\
\hline SE & & & & 0.0085 & & & & 0.0004 & 0.0002 & 0.0038 \\
\hline
\end{tabular}

Table 3 Performance of kNN for identifying Src inhibitors and non-inhibitors evaluated by 5 -fold cross validation study 
kNN model. After the 5-fold cross-validation, the parameter $\mathrm{k}=1$ was found to give the best performance of this work.

\section{Probabilistic neural network method}

PNN is a form of neural network that classifies objects based on Bayes' optimal decision rule [71] $h_{i} c_{i} f_{i}(\mathbf{x})>h_{j} c_{j} f_{j}$ $(\mathbf{x})$, where $h_{i}$ and $h_{j}$ are the prior probabilities, $c_{i}$ and $c_{j}$ are the costs of misclassification and $f_{i}(x)$ and $f_{j}(x)$ are the probability density function for class $i$ and $j$ respectively. A compound $\boldsymbol{x}$ is classified into class $i$ if the product of all the three terms is greater for class $i$ than for any other class $j$ (not equal to $i$ ). In most applications, the prior probabilities and costs of misclassifications are treated as being equal. The probability density function for each class for a univariate case can be estimated by using the Parzen's nonparametric estimator [72].

$$
g(\mathbf{x})=\frac{1}{n \sigma} \sum_{i=1}^{n} W\left(\frac{\mathbf{x}-\mathbf{x}_{i}}{\sigma}\right)
$$

where $n$ is the sample size, $\sigma$ is a scaling parameter which defines the width of the bell curve that surrounds each sample point, $W(d)$ is a weight function which has its largest value at $d=0$ and $\left(\boldsymbol{x}-\boldsymbol{x}_{i}\right)$ is the distance between the unknown vector and a vector in the training set. The Parzen's nonparametric estimator was later expanded by Cacoullos [73] for the multivariate case.

$$
\mathrm{g}\left(\mathrm{x}_{1}, \ldots, \mathrm{x}_{\mathrm{p}}\right)=\frac{1}{\mathrm{n} \sigma_{1} \ldots \sigma_{\mathrm{p}}} \sum_{\mathrm{i}=1}^{\mathrm{n}} \mathrm{W}\left(\frac{\mathrm{x}_{1}-\mathrm{x}_{1, \mathrm{i}}}{\sigma_{1}}, \ldots, \frac{\mathrm{x}_{\mathrm{p}}-\mathrm{x}_{\mathrm{p}, \mathrm{i}}}{\sigma_{\mathrm{p}}}\right)
$$

The Gaussian function is frequently used as the weight function because it is well behaved, easily calculated and satisfies the conditions required by Parzen's estimator. Thus the probability density function for the multivariate case becomes

$$
g(\mathbf{x})=\frac{1}{n} \sum_{i=1}^{n} \exp \left(-\sum_{j=1}^{p}\left(\frac{x_{j}-x_{i j}}{\sigma_{j}}\right)^{2}\right)
$$

The network architectures of PNN are determined by the number of compounds and descriptors in the training set. There are 4 layers in a PNN. The input layer provides input values to all neurons in the pattern layer and has as many neurons as the number of descriptors in the training set. The number of pattern neurons is determined by the total number of compounds in the training set. Each pattern neuron computes a distance measure between the input and the training case represented by that neuron and then subjects the distance measure to the Parzen's nonparameteric estimator. The summation layer has a neuron for each class and the neurons sum all the pattern neurons' output corresponding to members of that summation neuron's class to obtain the estimated probability density function for that class. The single neuron in the output layer then estimates the class of the unknown compound $\boldsymbol{x}$ by comparing all the probability density function from the summation neurons and choosing the class with the highest probability density function. The performance of PNN was validated by 5 -fold cross-validation in the same manner as in SVM model development. Table 4 shows the results of the 5-fold cross-validation of PNN model. After the 5-fold cross-validation, the parameter of the developed PNN models was chosen as 0.02 .

\section{Results and discussion}

Performance of SVM, kNN and PNN identification of Src inhibitors based on $\mathbf{5}$-fold cross validation test

The parameters of our SVM, kNN and PNN models were determined by 5 -fold cross-validation studies of Src inhibitors and non-inhibitors. The results of these tests for SVM, kNN and PNN are shown in Tables 2,3,4

\begin{tabular}{|c|c|c|c|c|c|c|c|c|c|c|}
\hline \multirow{2}{*}{$\begin{array}{l}\text { Cross - } \\
\text { validation }\end{array}$} & \multicolumn{4}{|c|}{ Src inhibitors } & \multicolumn{4}{|c|}{ Src non-inhibitors } & \multirow[t]{2}{*}{$\mathbf{Q}$} & \multirow[t]{2}{*}{$\mathrm{C}$} \\
\hline & $\begin{array}{l}\text { No of training/ testing } \\
\text { inhibitors }\end{array}$ & TP & FN & SE & $\begin{array}{l}\text { No of training/testing } \\
\text { non-inhibitors }\end{array}$ & TN & FP & SP & & \\
\hline 1 & $1362 / 341$ & 319 & 22 & $93.55 \%$ & $50654 / 12664$ & 12413 & 251 & $98.02 \%$ & $97.90 \%$ & 0.715 \\
\hline 2 & $1362 / 341$ & 324 & 17 & $95.01 \%$ & $50654 / 12664$ & 12380 & 284 & $97.76 \%$ & $97.69 \%$ & 0.702 \\
\hline 3 & $1362 / 341$ & 330 & 11 & $96.77 \%$ & $50654 / 12664$ & 12395 & 269 & $97.88 \%$ & $97.85 \%$ & 0.722 \\
\hline 4 & $1363 / 340$ & 330 & 10 & $97.06 \%$ & $50655 / 12663$ & 12389 & 274 & $97.84 \%$ & $97.82 \%$ & 0.720 \\
\hline 5 & $1363 / 340$ & 318 & 22 & $93.53 \%$ & $50655 / 12663$ & 12413 & 250 & $98.03 \%$ & $97.91 \%$ & 0.715 \\
\hline Average & & & & $95.19 \%$ & & & & $97.90 \%$ & $97.83 \%$ & 0.715 \\
\hline SD & & & & 0.0169 & & & & 0.0012 & 0.0009 & 0.0075 \\
\hline SE & & & & 0.0076 & & & & 0.0005 & 0.0004 & 0.0034 \\
\hline
\end{tabular}

Table 4 Performance of PNN for identifying Src inhibitors and non-inhibitors evaluated by 5-fold cross validation study 


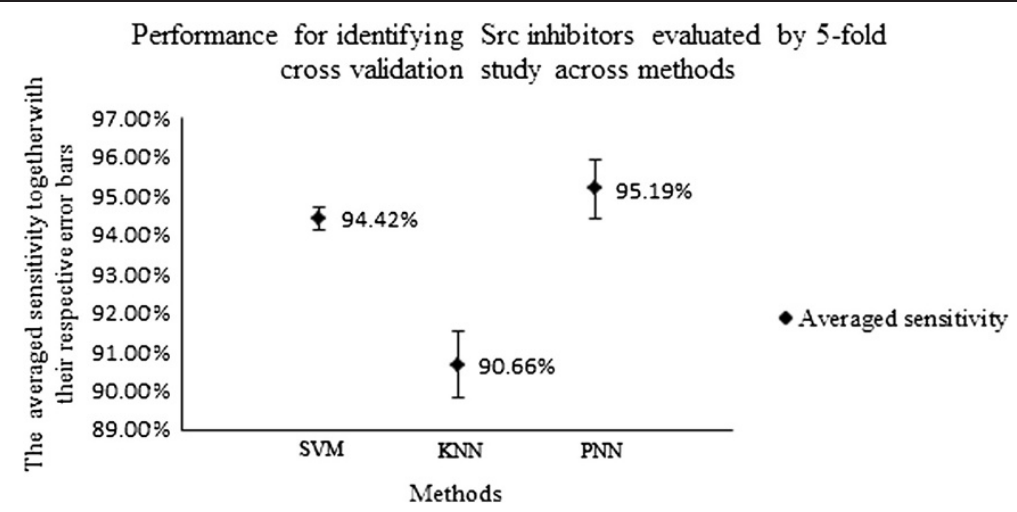

Figure 3 Performance for identifying Src inhibitors evaluated by $\mathbf{5}$-fold cross validation study across methods. Figure 3 is illustrating the 5-fold cross-validation studies of Src inhibitors across methods with the averaged sensitivity together with their respective error bars.

and Figure 3 respectively. Overall, the sensitivity of SVM, kNN and PNN is in the range of 93.53\% 95.01\%, $88.56 \% \sim 92.94 \%$ and $93.53 \% \sim 97.06 \%$, the specificity in the range of $99.81 \% \sim 99.90 \%, 99.57 \% \sim 99.77 \%$ and $97.76 \%$ $\sim 98.03 \%$, and overall accuracy Q in the range of $99.67 \%$ $99.76 \%$, 99.35\% 99.48\% and 97.69\% 97.91\% respectively. The inhibitor accuracies of our SVM are comparable to or slightly better than the reported accuracies of $58.3 \% \sim 67.3 \%$ for protein kinase C inhibitors by SVMRBF and CKD methods [74], 83\% for Lck inhibitors by SVM method [75], and 74\% 87\% for inhibitors of any of the 8 kinases (3 Ser/Thr and 5 Tyr kinases) by SVM, ANN, GA/kNN, and RP methods [76]. The non-inhibitor accuracies are comparable to the value of $99.9 \%$ for Lck inhibitors [75] and substantially better than the typical values of $77 \% \sim 96 \%$ of other studies $[74,76]$. Caution needs to be exercised about straightforward comparison of these results, which might be misleading because the outcome of VS strongly depends on the datasets and molecular descriptors used. Based on these rough comparisons, SVM appears to show good capability in identifying Src inhibitors at low false-hit rates.
Virtual screening performance of SVM in searching Src inhibitors from large compound libraries

As outlined in the methods section, we developed a SVM VS tool for searching Src inhibitors from large were developed by using Src kinases reported before 2011. The VS performance of SVM in identifying Src inhibitors reported since 2011 and in searching MDDR and PubChem databases is summarised in Table 5. The yield in searching Src inhibitors reported since 2011 is $70.45 \%$, which is comparable to the reported 50\% 94\% yields of various VS tools [77]. Strictly speaking, direct comparison of the reported performances of these VS tools is inappropriate because of the differences in the type, composition and diversity of compounds screened, and in the molecular descriptors, VS tools and their parameters used. The comparison cannot go beyond the statistics of accuracies.

We also evaluated virtual-hit rates and false-hit rates of SVM in screening compounds that resemble the structural and physicochemical properties of the known Src inhibitors by using 9,305 MDDR compounds similar to an Src inhibitor in the training dataset. Similarity was

Table 5 Virtual screening performance of support vector machines for identifying Src inhibitors from large compound libraries

\begin{tabular}{|c|c|c|}
\hline \multirow[t]{2}{*}{ Inhibitors in training set } & Number of inhibitors & 1703 \\
\hline & Number of chemical families covered by inhibitors & 493 \\
\hline \multirow[t]{3}{*}{ Inhibitors in Testing Set } & Number of Inhibitors & 44 \\
\hline & Number of Chemical Families Covered by Inhibitors & 35 \\
\hline & Percent of Inhibitors in Chemical Families Covered by Inhibitors in Training Set & $51.43 \%$ \\
\hline \multirow{5}{*}{$\begin{array}{l}\text { Virtual Screening } \\
\text { Performance }\end{array}$} & Yield & $70.45 \%$ \\
\hline & Number and Percent of Identified True Inhibitors Outside Training Chemical Families & $15(34.1 \%)$ \\
\hline & Number and Percent of 13.56M PubChemCompounds Identified as Inhibitors & $\begin{array}{l}44,843 \\
(0.33 \%)\end{array}$ \\
\hline & Number and Percent of the 168K MDDR Compounds Identified as Inhibitors & $1,496(0.89 \%$ \\
\hline & $\begin{array}{l}\text { Number and Percent of the 9,305 MDDR Compounds Similar to the Known Inhibitors Identified as } \\
\text { Inhibitors }\end{array}$ & $719(7.73 \%)$ \\
\hline
\end{tabular}


defined by Tanimoto similarity coefficient $\geq 0.9$ between a MDDR compound and its closest inhibitor [18]. This stricter similarity metric was used for conducting a stricter test of our SVM model. SVM identified 719 virtualhits from these 9,305 MDDR similarity compounds (virtual-hit rate $7.73 \%$ ), which suggests that SVM has some level of capability in distinguishing Src inhibitors from non-inhibitor similarity compounds. Significantly lower virtual-hit rates and thus false-hit rates were found in screening large libraries of $168 \mathrm{~K}$ MDDR and $13.56 \mathrm{M}$ PubChem compounds. The numbers of virtual-hits and virtual-hit rates in screening $168 \mathrm{~K}$ MDDR compounds are 1,496 and $0.89 \%$ respectively. The numbers of virtualhits and virtual-hit rates in screening $13.56 \mathrm{M}$ PubChem compounds are 44,843 and $0.33 \%$ respectively.

Substantial percentages of the MDDR virtual-hits belong to the classes of antineoplastic, tyrosine-specific protein kinase inhibitors, signal transduction inhibitors, antiangiogenic, and antiarthritic (Table 6, details in next section). As some of these virtual-hits may be true Src inhibitors, the false-hit rate of our SVM is at most equal to and likely less than the virtual-hit rate. Hence the false-hit rate is $<7.73 \%$ in screening 9,305 MDDR similarity compounds, $<0.89 \%$ in screening $168 \mathrm{~K}$ MDDR compounds, and $<0.33 \%$ in screening $13.56 \mathrm{M}$ PubChem compounds, which are comparable and in some cases better than the reported false-hit rates of $0.0054 \% \sim 8.3 \%$ of SVM [18,78], $0.08 \% \sim 3 \%$ of structure-based methods, $0.1 \%$ $\sim 5 \%$ by other machine learning methods, $0.16 \% \sim 8.2 \%$ by clustering methods, and $1.15 \% \sim 26 \%$ by pharmacophore models [77].

\section{Experimental test of a SVM identified virtual-hit}

Three virtual hits of the same novel scaffold from inhouse libraries not found in the known the Src inhibitor were evaluated for inhibitory activity against Src. Src kinase was incubated with substrates, compounds and ATP in a final buffer of $25 \mathrm{mM}$ HEPES (pH 7.4), $10 \mathrm{mM}$ $\mathrm{MgCl}_{2}, 0.01 \%$ Triton X-100, $100 \mu \mathrm{g} / \mathrm{mL} \mathrm{BSA,} 2.5 \mathrm{mM}$
DTT in 384-well plate with the total volume of $10 \mu \mathrm{l}$. The assay plate was incubated at $30^{\circ} \mathrm{C}$ for $1 \mathrm{~h}$ and stopped with the addition of equal volume of kinase glo plus reagent. The luminescence was read at envision. The signal was correlated with the amount of ATP present in the reaction and was inversely correlated with the kinase activity. One of three virtual hits showing in Figure 4 was found to inhibit Src at a moderate rate of $4.85 \%$ at $20 \mu \mathrm{M}$.

\section{Evaluation of SVM identified MDDR virtual-hits}

SVM identified MDDR virtual-hits were evaluated based on the known biological or therapeutic target classes specified in MDDR. Table 6 gives the MDDR classes that contain higher percentage $(\geq 3 \%)$ of SVM virtual-hits and the percentage values. We found that 623 (41.6\%) of the 1,496 virtual-hits belong to the antineoplastic class, which represent $2.9 \%$ of the 21,557 MDDR compounds in the class. In particular, 231 (15.4\%) of the virtual-hits belong to the tyrosine-specific protein kinase inhibitor class, which represent $19.6 \%$ of the 1,181 MDDR compounds in the class. Moreover, $194(13.0 \%)$ and 75 $(5.0 \%)$ of the virtual-hits belong to the signal transduction inhibitor and antiangiogenic classes, representing $9.5 \%$ and $4.6 \%$ of the 2,037 and 1,629 members in these classes respectively. Therefore, many of the SVM virtualhits are antineoplastic compounds that inhibit tyrosine kinases and possibly other kinases involved in signal transduction and angiogensis pathways. While some of these kinase inhibitors might be true Src inhibitors, a significant percentage of them are expected to arise from false selection of inhibitors of other kinases.

A total of $176(11.8 \%)$ SVM virtual-hits belong to the antiarthritic class. A primary feature of rheumatoid arthritis in synovial tissues is the abnormal stimulation of fibrin deposition, angiogenesis and proinflammatory processes, which are promoted by thrombin increased IL-6 production via the PAR1 receptor/PI-PLC/PKC alpha/c-Src/NF-kappaB and p300 signaling pathways

Table 6 MDDR classes that contain higher percentage ( $\geq 3 \%$ ) of SVM virtual-hits and the percentage values

\begin{tabular}{lll}
\hline $\begin{array}{l}\text { MDDR Classes that contain higher percentage } \\
(\geq \mathbf{3} \%) \text { of virtual hits }\end{array}$ & No of virtual hits in class & $\begin{array}{l}\text { Percentage of class members } \\
\text { selected as virtual hits }\end{array}$ \\
\hline Antineoplastic & 623 & $2.9 \%$ \\
Tyrosine-Specific Protein Kinase Inhibitor & 231 & $19.6 \%$ \\
Signal Transduction Inhibitor & 194 & $9.5 \%$ \\
Antiarthritic & 176 & $1.5 \%$ \\
Antiallergic/Antiasthmatic & 83 & $0.8 \%$ \\
Antihypertensive & 76 & $0.7 \%$ \\
Antiangiogenic & 75 & $4.6 \%$ \\
Treatment for Osteoporosis & 55 & $2.2 \%$ \\
Antidepressant & 49 & $0.8 \%$ \\
\hline
\end{tabular}

Virtual-hits are identified by SVMs in screening 168K MDDR compounds for Src inhibitors. The total number of SVM identified virtual hits is $1,496$. 


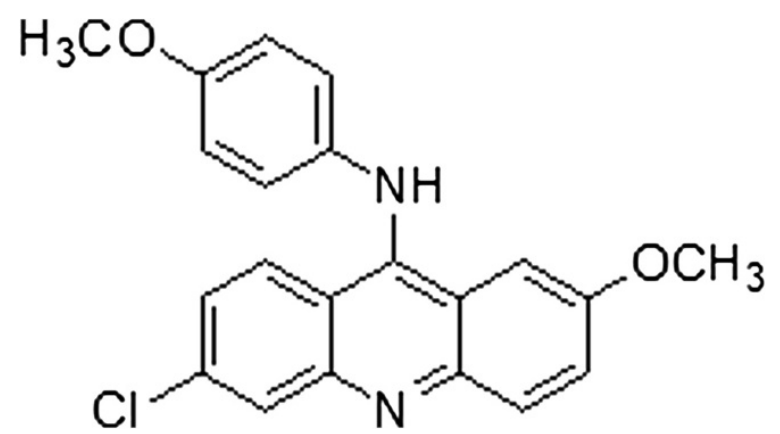

Figure 4 Virtual hit inhibiting Src at a moderate rate of $4.85 \%$ at $20 \mu \mathrm{M}$.

[79]. Therefore, Src inhibitors may have some effects against arthritis via interference with some of these processes. Moreover, several other kinases have been implicated in arthritis. An Abl inhibitor Gleevec has been reported to be effective in treatment of arthritis, which is probably due to its inhibition of other related kinases such as c-kit and PDGFR [80]. EGFR-like receptor stimulates synovial cells and its elevated activities may be involved in the pathogenesis of rheumatoid arthritis [78]. VEGF has been related to such autoimmune diseases as systemic lupus erythematosus, rheumatoid arthritis, and multiple sclerosis [81]. FGFR may partly mediates osteoarthritis [82]. PDGF-like factors stimulates the proliferative and invasive phenotype of rheumatoid arthritis synovial connective tissue cells [83]. Lck inhibition leads to immunosuppression and has been explored for the treatment of rheumatoid arthritis and asthma [84]. Therefore, some of the SVM virtual-hits in the antiarthritic class may be inhibitors of these kinases or their kinase-likes capable of producing antiarthritic activities.

Moreover, 83 (5.5\%), 76 (5.1\%), 55 (3.7\%) and 49 (3.3\%) of the SVM virtual hits are in the antiallergic/antiasthmatic, antihypertensive, osteoporosis treatment and antidepressant classes respectively. Src or Src family kinases have been implicated in and the respective inhibitors have shown observable effects against these diseases. For instance, Src family kinases and lipid mediators have been found to partly control allergic inflammation [85]. Inhibition of Src family kinase-dependent signaling cascades in mast cells may exert anti-allergic activity [86]. Upregulation of Src signaling has been suggested to be important in the profibrotic and proinflammatory actions of aldosterone in a genetic model of hypertension, which can be significantly reduced by mineralocorticoid receptor blocker and Src inhibitor [87]. Src signalling pathways play critical roles in osteoclasts and osteoblasts, and Src inhibitors have been developed as therapeutic agents for bone diseases $[88,89]$. Src-family protein tyrosine kinases negatively regulate cerebellar long-term depression, which can be recovered by the application of Src-family protein tyrosine kinase inhibitors [90]. Therefore, some of the SVM virtual hits in these four MDDR classes may be Src inhibitors or Src family kinase inhibitors capable of regulating allergic inflammation, hypertension, osteoporosis and depression respectively.

\section{Comparison of virtual screening performance of SVM with} those of other vrtual screening methods

To evaluate the level of performance of SVM and whether the performance is due to the SVM classification models or to the molecular descriptors used, SVM results were compared with those of three other VS methods based on the same molecular descriptors, training dataset of Src inhibitors reported before 2011, and the testing dataset of Src inhibitors reported since 2011 and 168K MDDR compounds. The three other VS methods include two similarity-based methods, Tanimotobased similarity searching and kNN methods, and an alternative machine learning method PNN. As shown in Table 7, the yield and maximum possible false-hit rate of the Tanimoto-based similarity searching, $\mathrm{kNN}$ and PNN methods are $36.84 \%$ and $5.54 \%, 38.64 \%$ and $2.49 \%$, and $50.00 \%$ and $2.60 \%$ respectively. Compared to these results, the yield of SVM is better than these similaritybased VS method, and the false-hit rate of SVM is significantly reduced by 6.22, 2.80, and 2.92 fold respectively. These suggests that SVM performance is due primarily to the SVM classification models rather than the molecular descriptors used, and SVM is capable of achieving comparable yield at substantially reduced false-hit rate as compared to both similarity-based approach and alternative machine learning method. Our results are consistent with the report that SVM shows mostly good performances both on classification and regression tasks, but other classification and regression methods proved to be very competitive [19].

\section{Does SVM select Src inhibitors or membership of compound families?}

To further evaluate whether SVM identifies Src inhibitors rather than membership of certain compound families, compound family distribution of the identified Src inhibitors and non-inhibitors were analyzed. $34.1 \%$ of the identified inhibitors belong to the families that contain no known Src inhibitors. For those families that contain at least one known Src inhibitor, $>70 \%$ of the compounds ( $>90 \%$ in majority cases) in each of these families were predicted as non-inhibitor by SVM. These results suggest that SVM identify Src inhibitors rather than membership to certain compound families. Some of the identified inhibitors not in the family of known inhibitors may serve as potential "novel" Src inhibitors. Therefore, as in the case shown by earlier studies [13], SVM has certain capacity for identifying novel active 
Table 7 Comparison of virtual screening performance of SVM with those of other methods

\begin{tabular}{|c|c|c|c|c|c|c|c|c|c|}
\hline \multirow[t]{2}{*}{ Method } & \multicolumn{2}{|c|}{ Inhibitors in training set } & \multicolumn{3}{|c|}{ Inhibitors in testing set } & \multicolumn{4}{|c|}{ Virtual screening performance } \\
\hline & $\begin{array}{l}\text { No of } \\
\text { inhibitors }\end{array}$ & $\begin{array}{l}\text { No of } \\
\text { chemical } \\
\text { families } \\
\text { covered by } \\
\text { inhibitors }\end{array}$ & $\begin{array}{l}\text { No of } \\
\text { inhibitors }\end{array}$ & $\begin{array}{l}\text { No of } \\
\text { chemical } \\
\text { families } \\
\text { covered by } \\
\text { inhibitors }\end{array}$ & $\begin{array}{l}\text { Percent of inhibitors in } \\
\text { chemical families } \\
\text { covered by inhibitors in } \\
\text { training set }\end{array}$ & Yield & $\begin{array}{l}\text { No and Percent of } \\
\text { identified true } \\
\text { inhibitors outside } \\
\text { training chemical } \\
\text { families }\end{array}$ & $\begin{array}{l}\text { No and Percent of } \\
\text { the } 168 \mathrm{~K} \text { MDDR } \\
\text { compounds } \\
\text { identified as } \\
\text { inhibitors }\end{array}$ & $\begin{array}{l}\text { No and Percent of the } 9,305 \\
\text { MDDR compounds similar to the } \\
\text { known inhibitors identified as } \\
\text { virtual inhibitors }\end{array}$ \\
\hline $\begin{array}{l}\text { Support } \\
\text { Vector } \\
\text { Machines }\end{array}$ & 1703 & 493 & 44 & 35 & $51.43 \%$ & $70.45 \%$ & 15(34.1\%) & $1,496(0.89 \%)$ & $719(7.73 \%)$ \\
\hline $\begin{array}{l}\text { Tanimoto } \\
\text { Similarity }\end{array}$ & & & & & & $36.84 \%$ & $9(20.5 \%)$ & $9,305(5.54 \%)$ & $9,305(100 \%)$ \\
\hline $\begin{array}{l}\text { K Nearest } \\
\text { Neighbour }\end{array}$ & & & & & & $38.64 \%$ & $10(22.7 \%)$ & $4,182(2.49 \%)$ & $1,169(12.57 \%)$ \\
\hline $\begin{array}{l}\text { Probabilistic } \\
\text { Neural } \\
\text { Network }\end{array}$ & & & & & & $50.0 \%$ & $13(29.5 \%)$ & $4,386(2.60 \%)$ & $1,184(12.72 \%)$ \\
\hline
\end{tabular}


compounds from sparse as well as regular-sized active datasets.

\section{Conclusions}

Our study suggested that SVM is capable of identifying Src inhibitors at comparable yield and in many cases substantially lower false-hit rate than those of typical VS tools reported in the literatures. It can be used for searching large compound libraries at sizes comparable to the $13.56 \mathrm{M}$ PubChem and $168 \mathrm{~K}$ MDDR compounds at low false-hit rates. The performance of SVM is substantially improved against several other VS method based on the same datasets and molecular descriptors, suggesting that the VS performance of SVM is primarily due to SVM classification models rather than the molecular descriptors used. Three SVM virtual hits of the same novel scaffold were experimentally tested, one of which showed moderate Src inhibition rate. Because of its high computing speed and generalization capability for covering highly diverse spectrum compounds, SVM can be potentially explored to develop useful VS tools to complement other VS methods or to be used as part of integrated VS tools in facilitating the discovery of Src inhibitors and other active compounds [91-93].

\section{Competing interests}

The authors declare that they have no competing interests.

\section{Authors' contributions}

BC Han conceived study, implemented the methods and wrote the manuscript with assistance from XH Ma, RY Zhao, JX Zhang, XN Wei, XH Liu, $X$ Liu and YZ Chen. The experiments were conducted by CL Zhang, CY Tan and $Y Y$ Jiang. All co-authors participated in study's design, coordination and manuscript drafting. All authors read and approved the final manuscript.

\section{Acknowledgements}

This work was supported in part by grants from Singapore Academic Research Fund R-148-000-083-112, National Natural Science Foundation of China Grant 30772651, Ministry of Science and Technology, $863 \mathrm{Hi}-\mathrm{Tech}$ Program Grant 2006AA020400.

\section{Author details}

${ }^{1}$ The Key Laboratory of Chemical Biology, Guangdong Province, The Graduate School at Shenzhen, Tsinghua University, Shenzhen, Guangdong 518055, People's Republic of China. ${ }^{2}$ Computation and Systems Biology, Singapore-MIT Alliance, National University of Singapore, E4-04-10, 4 Engineering Drive 3, Singapore 117576, Singapore. ${ }^{3}$ Bioinformatics and Drug Design Group, Department of Pharmacy, Centre for Computational Science and Engineering, National University of Singapore, Blk S16, Level 8, 3 Science Drive 2, Singapore 117543, Singapore. ${ }^{4}$ Central Research Institute of China Chemical Science and Technology, 20 Xueyuan Road, Haidian District, Beijing 100083, People's Republic of China.

Received: 13 July 2012 Accepted: 7 November 2012 Published: 23 November 2012

\section{References}

1. Brunton VG, Frame MC: Src and focal adhesion kinase as therapeutic targets in cancer. Curr Opin Pharmacol 2008, 8:427-432.

2. Gill AL, Verdonk M, Boyle RG, Taylor R: A comparison of physicochemical property profiles of marketed oral drugs and orally bioavailable anticancer protein kinase inhibitors in clinical development. Curr Top Med Chem 2007, 7:1408-1422.
3. Lee D, Gautschi O: Clinical development of SRC tyrosine kinase inhibitors in lung cancer. Clin Lung Cancer 2006, 7:381-384.

4. Hiscox S, Nicholson RI: Src inhibitors in breast cancer therapy. Expert Opin Ther Targets 2008, 12:757-767.

5. Lin LG, Xie H, Li HL, Tong LJ, Tang CP, Ke CQ, Liu QF, Lin LP, Geng MY, Jiang $H$, et al: Naturally occurring homoisoflavonoids function as potent protein tyrosine kinase inhibitors by c-Src-based high-throughput screening. J Med Chem 2008, 51:4419-4429.

6. Lee K, Kim J, Jeong KW, Lee KW, Lee Y, Song JY, Kim MS, Lee GS, Kim Y: Structure-based virtual screening of Src kinase inhibitors. Bioorg Med Chem 2009, 17:3152-3161.

7. Farard J, Lanceart G, Loge C, Nourrisson MR, Cruzalegui F, Pfeiffer B, Duflos M: Design, synthesis and evaluation of new 6-substituted-5-benzyloxy-4oxo-4H-pyran-2-carboxamides as potential Src inhibitors. J Enzyme Inhib Med Chem 2008, 23:629-640.

8. Alfaro-Lopez J, Yuan W, Phan BC, Kamath J, Lou Q, Lam KS, Hruby VJ: Discovery of a novel series of potent and selective substrate-based inhibitors of p60csrc protein tyrosine kinase: conformational and topographical constraints in peptide design. J Med Chem 1998, 41:2252-2260.

9. Chen P, Doweyko AM, Norris D, Gu HH, Spergel SH, Das J, Moquin RV, Lin J, Wityak J, Iwanowicz EJ, et al: Imidazoquinoxaline Src-family kinase p56Lck inhibitors: SAR, QSAR, and the discovery of (S)-N-(2-chloro-6methylphenyl)-2-(3-methyl-1-piperazinyl)imidazo- [1,5-a]pyrido[3,2-e] pyrazin-6-amine (BMS-279700) as a potent and orally active inhibitor with excellent in vivo antiinflammatory activity. J Med Chem 2004, 47:4517-4529.

10. Shoichet BK: Virtual screening of chemical libraries. Nature 2004, 432:862-865.

11. Ghosh S, Nie A, An J, Huang Z: Structure-based virtual screening of chemical libraries for drug discovery. Curr Opin Chem Biol 2006, 10:194-202.

12. Li H, Yap CW, Ung CY, Xue Y, Li ZR, Han LY, Lin HH, Chen YZ: Machine learning approaches for predicting compounds that interact with therapeutic and ADMET related proteins. J Pharm Sci 2007, 96:2838-2860.

13. Han LY, Ma XH, Lin HH, Jia J, Zhu F, Xue Y, Li ZR, Cao ZW, Ji ZL, Chen YZ: A support vector machines approach for virtual screening of active compounds of single and multiple mechanisms from large libraries at an improved hit-rate and enrichment factor. J Mol Graph Model 2008, 26:1276-1286.

14. Jorissen RN, Gilson MK: Virtual screening of molecular databases using a support vector machine. J Chem Inf Model 2005, 45:549-561.

15. Lepp Z, Kinoshita T, Chuman H: Screening for new antidepressant leads of multiple activities by support vector machines. J Chem Inf Model 2006, 46:158-167.

16. Glick $M$, Jenkins JL, Nettles JH, Hitchings $H$, Davies JW: Enrichment of highthroughput screening data with increasing levels of noise using support vector machines, recursive partitioning, and laplacian-modified naive bayesian classifiers. J Chem Inf Model 2006, 46:193-200.

17. Hert J, Willett P, Wilton DJ, Acklin P, Azzaoui K, Jacoby E, Schuffenhauer A: New methods for ligand-based virtual screening: use of data fusion and machine learning to enhance the effectiveness of similarity searching. J Chem Inf Model 2006, 46:462-470.

18. Ma XH, Wang R, Yang SY, Li ZR, Xue Y, Wei YC, Low BC, Chen YZ: Evaluation of virtual screening performance of support vector machines trained by sparsely distributed active compounds. J Chem Inf Model 2008, 48:1227-1237.

19. Mayer D, Leisch F, Hornik K: The support vector machine under test. Neurocomputing 2003, 55:169-186.

20. Verdonk ML, Berdini V, Hartshorn MJ, Mooij WT, Murray CW, Taylor RD, Watson P: Virtual screening using protein-ligand docking: avoiding artificial enrichment. J Chem Inf Comput Sci 2004, 44:793-806.

21. Huang N, Shoichet BK, Irwin JJ: Benchmarking sets for molecular docking. J Med Chem 2006, 49:6789-6801.

22. Altmann E, Missbach M, Green J, Susa M, Wagenknecht HA, Widler L: 7-Pyrrolidinyl- and 7-piperidinyl-5-aryl-pyrrolo[2,3-d]pyrimidines-potent inhibitors of the tyrosine kinase c-Src. Bioorg Med Chem Lett 2001, 11:853-856.

23. Widler L, Green J, Missbach M, Susa M, Altmann E: 7-Alkyl- and 7cycloalkyl-5-aryl-pyrrolo[2,3-d]pyrimidines-potent inhibitors of the tyrosine kinase c-Src. Bioorg Med Chem Lett 2001, 11:849-852.

24. Missbach M, Altmann E, Widler L, Susa M, Buchdunger E, Mett H, Meyer T, Green J: Substituted 5,7-diphenyl-pyrrolo[2,3d]pyrimidines: potent 
inhibitors of the tyrosine kinase c-Src. Bioorg Med Chem Lett 2000, 10:945-949.

25. Klutchko SR, Hamby JM, Boschelli DH, Wu Z, Kraker AJ, Amar AM, Hartl BG, Shen C, Klohs WD, Steinkampf RW, et al: 2-Substituted aminopyrido[2,3-d] pyrimidin-7(8H)-ones. structure-activity relationships against selected tyrosine kinases and in vitro and in vivo anticancer activity. $J$ Med Chem 1998, 41:3276-3292.

26. Noronha G, Barrett K, Boccia A, Brodhag T, Cao J, Chow CP, Dneprovskaia E, Doukas J, Fine R, Gong X, et al: Discovery of [7-(2,6-dichlorophenyl)-5methylbenzo [1,2,4]triazin-3-yl]-[4-(2-pyrrolidin-1-ylethoxy)phenyl]aminea potent, orally active Src kinase inhibitor with anti-tumor activity in preclinical assays. Bioorg Med Chem Lett 2007, 17:602-608.

27. Liu T, Lin Y, Wen X, Jorissen RN, Gilson MK: BindingDB: a web-accessible database of experimentally determined protein-ligand binding affinities. Nucleic Acids Res 2007, 35:D198-201.

28. Keseru GM, Makara GM: The influence of lead discovery strategies on the properties of drug candidates. Nat Rev Drug Discov 2009, 8:203-212.

29. Keseru GM, Makara GM: Hit discovery and hit-to-lead approaches. Drug Discov Today 2006, 11:741-748.

30. Bocker A, Schneider G, Teckentrup A: NIPALSTREE: a new hierarchical clustering approach for large compound libraries and its application to virtual screening. J Chem Inf Model 2006, 46:2220-2229.

31. Oprea Tl, Gottfries J: Chemography: the art of navigating in chemical space. J Comb Chem 2001, 3:157-166.

32. Reymond TFJ-L: Virtual Exploration of the Chemical Universe up to 11 Atoms of C, N, O, F: Assembly of 26.4 Million Structures (110.9 Million Stereoisomers) and Analysis for New Ring Systems, Stereochemistry, Physicochemical Properties, Compound Classes, and Drug Discovery. J Chem Inf Model 2007, 47:342-353.

33. Koch MA, Schuffenhauer A, Scheck M, Wetzel S, Casaulta M, Odermatt A, Ertl $\mathrm{P}$, Waldmann $\mathrm{H}$ : Charting biologically relevant chemical space: a structural classification of natural products (SCONP). Proc Natl Acad Sc USA 2005, 102:17272-17277.

34. Kinoshita K, Kobayashi T, Asoh K, Furuichi N, Ito T, Kawada H, Hara S, Ohwada J, Hattori K, Miyagi T, et al: 9-substituted 6,6-dimethyl-11-oxo6,11-dihydro-5H-benzo[b]carbazoles as highly selective and potent anaplastic lymphoma kinase inhibitors. J Med Chem 2011, 54:6286-6294.

35. Schmidt S, Preu L, Lemcke T, Totzke F, Schachtele C, Kubbutat MH, Kunick C: Dual IGF-1R/SRC inhibitors based on a N'-aroyl-2-(1H-indol-3-yl)-2oxoacetohydrazide structure. Eur J Med Chem 2011, 46:2759-2769.

36. Crew AP, Bhagwat SV, Dong H, Bittner MA, Chan A, Chen X, Coate H, Cooke A, Gokhale PC, Honda A, et al: Imidazo[1,5-a]pyrazines: orally efficacious inhibitors of mTORC1 and mTORC2. Bioorg Med Chem Lett 2011, 21:2092-2097.

37. Pevet I, Brule C, Tizot A, Gohier A, Cruzalegui F, Boutin JA, Goldstein S: Synthesis and pharmacological evaluation of thieno[2,3-b]pyridine derivatives as novel c-Src inhibitors. Bioorg Med Chem 2011, 19:2517-2528.

38. Guagnano V, Furet P, Spanka C, Bordas V, Le Douget M, Stamm C, Brueggen J, Jensen MR, Schnell C, Schmid H, et al: Discovery of 3-(2,6-dichloro-3, 5-dimethoxy-phenyl)-1-\{6-[4-(4-ethyl-piperazin-1-yl)-phenylamin o]pyrimidin-4-yl\}-1-methyl-urea (NVP-BGJ398), a potent and selective inhibitor of the fibroblast growth factor receptor family of receptor tyrosine kinase. J Med Chem 2011, 54:7066-7083.

39. Kumar A, Ahmad I, Chhikara BS, Tiwari R, Mandal D, Parang K: Synthesis of 3-phenylpyrazolopyrimidine-1,2,3-triazole conjugates and evaluation of their Src kinase inhibitory and anticancer activities. Bioorg Med Chem Lett 2011, 21:1342-1346

40. Fang H, Tong W, Shi LM, Blair R, Perkins R, Branham W, Hass BS, Xie Q, Dial $\mathrm{SL}$, Moland CL, Sheehan DM: Structure-activity relationships for a large diverse set of natural, synthetic, and environmental estrogens. Chem Res Toxicol 2001, 14:280-294.

41. Tong $W$, Xie $Q$, Hong $H$, Shi L, Fang $H$, Perkins R: Assessment of prediction confidence and domain extrapolation of two structure-activity relationship models for predicting estrogen receptor binding activity. Environ Health Perspect 2004, 112:1249-1254.

42. Jacobs MN: In silico tools to aid risk assessment of endocrine disrupting chemicals. Toxicology 2004, 205:43-53.

43. Hu JY, Aizawa T: Quantitative structure-activity relationships for estrogen receptor binding affinity of phenolic chemicals. Water Res 2003, 37:1213-1222

44. Byvatov E, Fechner U, Sadowski J, Schneider G: Comparison of support vector machine and artificial neural network systems for drug/nondrug classification. J Chem Inf Comput Sci 2003, 43:1882-1889.
45. Doniger S, Hofman T, Yeh J: Predicting CNS Permeability of Drug Molecules:Comparison of Neural Network and Support Vector Machine Algorithms. J Comput Biol 2002, 9:849-864.

46. He L, Jurs PC, Custer LL, Durham SK, Pearl GM: Predicting the Genotoxicity of Polycyclic Aromatic Compounds from Molecular Structure with Different Classifiers. Chem Res Toxicol 2003, 16:1567-1580.

47. Snyder RD, Pearl GS, Mandakas G, Choy WN, Goodsaid F, Rosenblum IY: Assessment of the sensitivity of the computational programs DEREK, TOPKAT, and MCASE in the prediction of the genotoxicity of pharmaceutical molecules. Environ Mol Mutagen 2004, 43:143-158.

48. Xue Y, Li ZR, Yap CW, Sun LZ, Chen X, Chen YZ: Effect of Molecular Descriptor Feature Selection in Support Vector Machine Classification of Pharmacokinetic and Toxicological Properties of Chemical Agents. J Chem Inf Comput Sci 2004, 44:1630-1638.

49. Yap CW, Cai CZ, Xue Y, Chen YZ: Prediction of torsade-causing potential of drugs by support vector machine approach. Toxicol Sci 2004, 79:170-177.

50. Yap CW, Chen YZ: Quantitative Structure-Pharmacokinetic Relationships for drug distribution properties by using general regression neural network. J Pharm Sci 2005, 94:153-168.

51. Zernov W, Balakin KV, Ivaschenko AA, Savchuk NP, Pletnev IV: Drug discovery using support vector machines. The case studies of drug likeness, agrochemical-likeness, and enzyme inhibition predictions. J Chem Inf Comput Sci 2003, 43:2048-2056.

52. Xue Y, Yap CW, Sun LZ, Cao ZW, Wang JF, Chen YZ: Prediction of Pglycoprotein substrates by a support vector machine approach. J Chem Inf Comput Sci 2004, 44:1497-1505.

53. Todeschini R, Consonni V: Handbook of Molecular Descriptors. Weinheim: Wiley-VCH; 2000.

54. Miller KJ: Additive methods in molecular polarizability. J Am Chem Soc 1990, 112:8533-8542.

55. Schultz HP: Topological organic chemistry. 1. graph theory and topological indices of alkanes. J Chem Inf Comput Sci 1989, 29:227-228.

56. Hall LH, Kier LB: Electrotopological state indices for atom types: a novel combination of electronic, topological and valence state information. J Chem Inf Comput Sci 1995, 35:1039-1045.

57. Vapnik VN: The nature of statistical learning theory. New York: Springer; 1995.

58. Burges CJC: A tutorial on support vector machines for pattern recognition. Data Min Knowl Disc 1998, 2:127-167.

59. Pochet N, De Smet F, Suykens JA, De Moor BL: Systematic benchmarking of microarray data classification: assessing the role of non-linearity and dimensionality reduction. Bioinformatics 2004, 20:3185-3195.

60. Li F, Yang Y: Analysis of recursive gene selection approaches from microarray data. Bioinformatics 2005, 21:3741-3747.

61. Cui LYH J, Lin HH, Zhang HL, Tang ZQ, Zheng CJ, Cao ZW, Chen YZ: Prediction of MHC-Binding Peptides of Flexible Lengths from SequenceDerived Structural and Physicochemical Properties. Mol Immunol 2007, 44:866-877.

62. Yap CW, Chen YZ: Prediction of cytochrome P450 3A4, 2D6, and 2C9 inhibitors and substrates by using support vector machines. J Chem Inf Model 2005, 45:982-992.

63. Grover II, Singh II, Bakshi II: Quantitative structure-property relationships in pharmaceutical research - Part 2. Pharm Sci Technol Today 2000, 3:50-57.

64. Trotter MWB, Buxton BF, Holden SB: Support vector machines in combinatorial chemistry. Meas Control 2001, 34:235-239.

65. Burbidge R, Trotter M, Buxton B, Holden S: Drug design by machine learning: support vector machines for pharmaceutical data analysis. Comput Chem 2001, 26:5-14

66. Czerminski R, Yasri A, Hartsough D: Use of support vector machine in pattern classification: Application to QSAR studies. Quant Struct-Act Rel 2001, 20:227-240.

67. Matthews BW: Comparison of the predicted and observed secondary structure of T4 phage lysozyme. Biochim Biophys Acta 1975, 405:442-451.

68. Willett P: Chemical similarity searching. J Chem Inf Comput Sci 1998, 38:983-996.

69. Bostrom J, Hogner A, Schmitt S: Do structurally similar ligands bind in a similar fashion? J Med Chem 2006, 49:6716-6725.

70. Johnson RA, Wichern DW: Applied multivariate statistical analysis. Englewood Cliffs, NJ: Prentice Hall; 1982.

71. Specht DF: Probabilistic neural networks. Neural Netw 1990, 3:109-118.

72. Parzen E: On estimation of a probability density function and mode. Ann Math Stat 1962, 33:1065-1076. 
73. Cacoullos T: Estimation of a multivariate density. Ann / Stat Math 1966, 18:179-189.

74. Chen B, Harrison RF, Papadatos G, Willett P, Wood DJ, Lewell XQ, Greenidge $P$, Stiefl N: Evaluation of machine-learning methods for ligand-based virtual screening. J Comput Aided Mol Des 2007, 21:53-62.

75. Liew CY, Ma XH, Liu X, Yap CW: SVM Model for Virtual Screening of Lck Inhibitors. J Chem Inf Model 2009, 4:877-885.

76. Briem H, Gunther J: Classifying "kinase inhibitor-likeness" by using machine-learning methods. Chembiochem 2005, 6:558-566.

77. Ma XH, Jia J, Zhu F, Xue Y, Li ZR, Chen YZ: Comparative analysis of machine learning methods in ligand based virtual screening of large compound libraries. Comb Chem High Throughput Screen 2009, 12:344-357.

78. Yamane S, Ishida S, Hanamoto Y, Kumagai K, Masuda R, Tanaka K, Shiobara $\mathrm{N}$, Yamane N, Mori T, Juji T, et al: Proinflammatory role of amphiregulin, an epidermal growth factor family member whose expression is augmented in rheumatoid arthritis patients. J Inflamm (Lond) 2008, 5:5.

79. Chiu YC, Fong YC, Lai CH, Hung CH, Hsu HC, Lee TS, Yang RS, Fu WM, Tang $\mathrm{CH}$ : Thrombin-induced IL-6 production in human synovial fibroblasts is mediated by PAR1, phospholipase C, protein kinase C alpha, c-Src, NF-kappa B and p300 pathway. Mol Immunol 2008, 45:1587-1599.

80. Paniagua RT, Sharpe O, Ho PP, Chan SM, Chang A, Higgins JP, Tomooka BH, Thomas FM, Song JJ, Goodman SB, et al: Selective tyrosine kinase inhibition by imatinib mesylate for the treatment of autoimmune arthritis. J Clin Invest 2006, 116:2633-2642.

81. Carvalho JF, Blank M, Shoenfeld Y: Vascular endothelial growth factor (VEGF) in autoimmune diseases. J Clin Immunol 2007, 27:246-256.

82. Daouti S, Latario B, Nagulapalli S, Buxton F, Uziel-Fusi S, Chirn GW, Bodian D, Song C, Labow M, Lotz M, et al: Development of comprehensive functional genomic screens to identify novel mediators of osteoarthritis. Osteoarthritis Cartilage 2005, 13:508-518.

83. Remmers EF, Sano H, Wilder RL: Platelet-derived growth factors and heparin-binding (fibroblast) growth factors in the synovial tissue pathology of rheumatoid arthritis. Semin Arthritis Rheum 1991, 21:191-199.

84. Meyn MA 3rd, Smithgall TE: Small molecule inhibitors of Lck: the search for specificity within a kinase family. Mini Rev Med Chem 2008, 8:628-637.

85. Rivera J, Olivera A: Src family kinases and lipid mediators in control of allergic inflammation. Immunol Rev 2007, 217:255-268.

86. Lee JH, Kim JW, Ko NY, Mun SH, Kim do K, Kim JD, Won HS, Shin HS, Kim HS, Her E, et al: Mast cell-mediated allergic response is suppressed by Sophorae flos: inhibition of SRC-family kinase. Exp Biol Med (Maywood) 2008, 233:1271.

87. Callera GE, Montezano AC, Yogi A, Tostes RC, He Y, Schiffrin EL, Touyz RM: c-Src-dependent nongenomic signaling responses to aldosterone are increased in vascular myocytes from spontaneously hypertensive rats. Hypertension 2005, 46:1032-1038.

88. Metcalf CA 3rd, van Schravendijk MR, Dalgarno DC, Sawyer TK: Targeting protein kinases for bone disease: discovery and development of Src inhibitors. Curr Pharm Des 2002, 8:2049-2075.

89. Shakespeare WC, Wang Y, Bohacek R, Keenan T, Sundaramoorthi R, Metcalf C 3rd, Dilauro A, Roeloffzen S, Liu S, Saltmarsh J, et al: SAR of carbonlinked, 2-substituted purines: synthesis and characterization of AP23451 as a novel bone-targeted inhibitor of Src tyrosine kinase with in vivo anti-resorptive activity. Chem Biol Drug Des 2008, 71:97-105.

90. Tsuruno S, Kawaguchi SY, Hirano T: Src-family protein tyrosine kinase negatively regulates cerebellar long-term depression. Neurosci Res 2008, 61:329-332.

91. Vidal D, Thormann M, Pons M: A novel search engine for virtual screening of very large databases. J Chem Inf Model 2006, 46:836-843.

92. Stiefl N, Zaliani A: A knowledge-based weighting approach to ligandbased virtual screening. J Chem Inf Model 2006, 46:587-596.

93. Rella M, Rushworth CA, Guy JL, Turner AJ, Langer T, Jackson RM: Structurebased pharmacophore design and virtual screening for novel angiotensin converting enzyme 2 inhibitors. J Chem Inf Model 2006, 46:708-716.

\section{doi:10.1186/1752-153X-6-139}

Cite this article as: Han et al:: Development and experimental test of support vector machines virtual screening method for searching Src inhibitors from large compound libraries. Chemistry Central Journal 2012 6:139.

Publish with ChemistryCentral and every
scientist can read your work free of charge
"Open access provides opportunities to our
colleagues in other parts of the globe, by allowing
anyone to view the content free of charge."
W. Jeffery Hurst, The Hershey Company.
- available free of charge to the entire scientific community
- peer reviewed and published immediately upon acceptance
- cited in PubMed and archived on PubMed Central
- yours - you keep the copyright
submit your manuscript here:
http://www.chemistrycentral.com/manuscript/

